\title{
ARMONIZAR ALMA Y CUERPO A TRAVÉS DE LA BELLEZA. LA APORTACIÓN DEL IDEALISMO \\ Magdalena Bosch
}

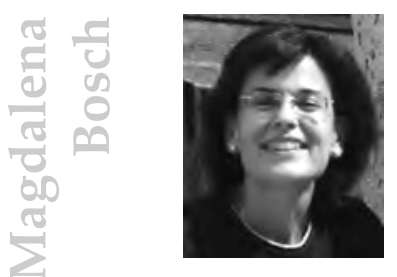

Doctora en Filosofía, Universidad de Barcelona. El Ministerio de Educación y Ciencia [España], le concedió una beca de formación de personal investigador para el período 1993-1996, año en que defendió su tesis: Metafísica de la intencionalidad. Ha realizado estancias de investigación posdoctoral en Roma (1996), Boston (1999), Pamplona (2001) y Munich (2004 y 2008). Sus temas de investigación giran en torno a la intencionalidad y la belleza. Ha publicado el libro Metafísica de la intencionalidad y varios artículos en revistas internacionales y españolas sobre Aristóteles, romanticismo, ética y estética. Actualmente es profesora Titular de Filosofía en la Facultad de Humanidades de la Universitat Internacional de Catalunya (Barcelona) y dirige el grupo de investigación: «Identidad y alteridad. Lecturas modernas de Aristóteles».

Correo electrónico: [mbosch@cir.uic.es].

\section{RESUMEN}

Uno de los grandes desafíos de la actividad educativa es aprender a armonizar alma y cuerpo; es un reto personal — de cada sujeto singular-, pero en el que se necesitan recursos que la pedagogía puede estudiar y enseñar.

La unión de alma y cuerpo es también uno de los más antiguos problemas de la filosofía, tanto en una aproximación teórica como por sus consecuencias prácticas. (Además de las reflexiones metafísicas que pueden realizarse en torno a este tema).

El propósito de este escrito es redescubrir algunas sugerencias del idealismo acerca de un equilibrio posible entre alma y cuerpo. Me referiré 
aquí a una parte muy concreta del idealismo: aquella que ofrece una visión positiva del hombre, y que se caracteriza por su optimismo, más que por la abstracción. Se trata del momento más moderado del Romanticismo, que surge en sus inicios.

Palabras clave: educación del carácter; educación emocional; cuerpo y alma; experiencia estética.

\section{ABSTRACT}

One of the greatest challenges facing teaching is learning how to harmonize body and soul. It is a personal challenge, for each individual; but it needs resources that the Pedagogy can study and teach. The union of body and soul is also one of the most ancient philosophical problems, in its theoretical approach as in its practical application. There are also the metaphysical considerations that can be made about this subject.

The aim of this article is to rediscover some of the suggestions from German Idealism which relate to the balance between body and soul. I will refer to a very specific part of this Idealism: one in which we can find a positive view of man, that is characterised by his optimism more than him being an abstract idea. This moderate view of man appeared specifically in the early period of Romanticism.

Key words: education of the character; emotional education; body and soul; aesthetic experience.

\section{INTRODUCCIÓN SOBRE EL IDEALISMO}

«Idealismo» no es un término unívoco. Se llama así al sistema de pensamiento hegeliano; pero también coloquialmente a la visión optimista — «ideal»— del mundo y del ser humano. Me referiré a una tercera acepción, a camino entre las dos mencionadas, y que consiste en una visión esperanzada de la vida, pero anclada en la realidad. Es una versión filosófica del idealismo, pero más cercana a la vida y a la realidad que la de Hegel. Nace entre 1798 y 1800, cuando se publica en Berlín la revista 
Athaeneum. En torno a esa publicación se reunieron espíritus afines que compartían sus más vivos intereses.

Algunos de ellos formarán parte de ese movimiento que pasa a la historia con el nombre de Sturm und Drang ${ }^{1}$, pero que en sus orígenes no es tan tormentoso ni impetuoso como ese nombre sugiere. Los pensadores que forman parte de este grupo comparten la admiración por la naturaleza, la exaltación del artista, el anhelo por la antigua Grecia y un profundo amor a la belleza. La inspiración poética de sus escritos y discusiones, la temática tratada — tan focalizada en lo bello y en el arte-, esas sensibilidades que veían con matices de extraordinaria precisión, la hondura de tales aspectos y factores, han hecho que sean más frecuentes las valoraciones literarias que las filosóficas. No en vano la mayoría de ellos consideró la poesía como una actividad superior a todas las demás.

Además de los rasgos característicos ya mencionados, destaca el rechazo de la Ilustración y del racionalismo kantiano. Ciertamente son numerosos los textos, por ejemplo de Novalis o Schiller, en que hallamos protestas contra la razón ilustrada: su rigidez, su pretensión de medirlo todo y proporcionar explicaciones empíricas a cualquier fenómeno. El espíritu poético de esos autores se rebela, ofreciendo una visión de los fenómenos naturales casi opuesta a la visión científica. Ellos subrayan la armonía de la naturaleza como categoría estética. Pero al mismo tiempo que repudian las medidas y el control de la dinámica de la vida natural, entienden que su armonía se debe a unas leyes que conocemos gracias a las ciencias positivas. Probablemente no deba considerarse la suya una rebeldía contra la razón en sí y de forma generalizada, sino más bien contra un modo concreto de presentarla o de imponer su dominio.

Estos elementos desembocan en un tema común, tratado de diversas formas, y que se revela central: la relación entre lo espiritual y lo material, $y$, en consecuencia, abren la posibilidad de un nuevo enfoque de la relación alma-cuerpo y de la posibilidad de reconciliarlos, especialmente teniendo en cuenta la función conciliadora de la belleza: afín al alma, a sus

En alemán: tormenta e ímpetu. 
regiones más espirituales; a la vez que a su vida afectiva y a la sensibilidad que habita en el cuerpo.

\section{EL REFLEJO DEL ALMA EN LA NATURALEZA}

Es conocida la preferencia romántica por la naturaleza y su contemplación. En Hiperión, las descripciones del paisaje constituyen un asiduo pretexto para describir estados del alma. Hölderlin tomó ocasión del amanecer, del sol, de los árboles y el aire, para transmitir unas veces el despertar interior, la ilusión; otras, el pesar y la decepción. Todos los elementos naturales parecen constituir un lenguaje de sentimientos tan variados como el alma humana es capaz de experimentarlos y, junto al reflejo del alma, se reconoce en la naturaleza un reflejo de Dios: cielos, prados y montes son, también, manifestaciones de la divinidad.

Bajo la carga poética de tales imágenes, su belleza plástica, su fuerza descriptiva, late una comprensión profunda de la condición humana y su armonía interna. Otro buen ejemplo lo hallamos en el discurso que Schelling pronunció en 1807, La relación del arte con la naturaleza, en el que aborda el problema de la naturaleza precisamente desde el punto de vista de su relación con el alma. En él considera la unidad de alma y cosmos:

El espíritu de la naturaleza no está contrapuesto al alma nada más que en apariencia, porque en sí mismo es el instrumento de su manifestación. Produce, ciertamente, la oposición de las cosas, pero sólo para que la única esencia pueda aparecer como la más alta dulzura y reconciliación de todas las fuerzas ${ }^{2}$.

La unidad del alma con la naturaleza que Hölderlin describía poéticamente, la aborda Schelling como problema propiamente filosófico, y conduce el tema a la esencia de la naturaleza, donde se realiza la unidad de todo, y que permanece vinculada al absoluto. Y no sólo en el mencionado discurso, sino también en su primera obra de reconocida relevancia,

2 Friedrich Schelling, La relación del arte con la naturaleza, p. 86-87. 
publicada en 1800, Sistema del idealismo trascendental, encontramos fragmentos en que, sin alusión alguna al arte, apunta directamente a la unidad de naturaleza y alma. En estas ocasiones, esa unidad es posible gracias a la inteligencia humana y su comprensión del cosmos. La expresión es menos poética, quizás, que en el discurso de 1807, pero el concepto es el mismo: las leyes presentes en la naturaleza, desveladas por la inteligencia, son una forma comprensible para el conocimiento humano, por el vínculo que crea entre ellos la existencia de una causa común:

La más alta consumación de la ciencia natural sería la completa espiritualización de todas las leyes de la naturaleza en leyes de intuición y pensamiento. El fenómeno (la materia) debe desaparecer totalmente y permanecer sólo las leyes (la forma). Por tanto, el mayor ordenamiento emerge en la misma naturaleza, lo más externo desaparece, los mismos fenómenos se hacen más mentales, y escapa completamente a las medidas ${ }^{3}$.

Schelling distingue materia y forma en la naturaleza, y considera especialmente admirable la forma porque manifiesta las leyes, con las que se identifica, y que constituyen la posibilidad de lo bello natural que los humanos podemos apreciar. Se advierte en estas consideraciones cierto platonismo, pero también reconocemos su afinidad con propuestas de contemporáneos suyos.

Es el caso de Fichte, que defiende la fiabilidad del conocimiento basado en lo formal, en conceptos y en leyes. En Doctrina de la ciencia, considera que mientras el hombre se detiene en las percepciones sensibles, sólo posee opiniones (conocimiento dudoso). Únicamente en los conceptos se halla la convicción (conocimiento cierto). Sólo el conocimiento de las leyes es sólido y seguro. La postura de Kant es parecida. Ya en 1790 había destacado el papel de las leyes de la naturaleza, en la Crítica del juicio:

La belleza independiente natural nos descubre una técnica de la naturaleza que la hace representable como un sistema según leyes cuyo principio no encontramos en toda nuestra facultad del entendimiento ${ }^{4}$.

3 Id., Sistema del idealismo trascendental, parág. 1, 4, A (340-341), p. 6.

4 Immanuel Kant, Crítica del juicio, parág. 23, p. 241. 
La belleza va unida a leyes: belleza de la naturaleza es la forma en que se presenta un sistema de leyes.

Esta representación del sistema legislativo natural por medio de la belleza no es del todo evidente, sino más bien tenue, algo velada. Por eso, solamente las almas más nobles tienen la capacidad de intuir esas leyes y gozar de la belleza con que se manifiestan:

Si un hombre que tiene gusto bastante para juzgar productos de las bellas artes con la mayor exactitud y finura deja sin pena la estancia donde se encuentran las bellezas que entretienen la vanidad y otros goces sociales, y se vuelve hacia lo bello de la naturaleza para encontrar aquí, por decirlo así, voluptuosidad para su espíritu en una hilera de pensamientos que no puede desarrollar jamás completamente, entonces consideraremos ésa su elección con alto respeto y supondremos en él un alma bella, cosa que no puede pretender perito ni aficionado alguno del arte, por el mérito del interés que toma en sus objetos ${ }^{5}$.

La preferencia por lo natural distingue las almas en que prevalece la capacidad de gozo espiritual sobre goces más vulgares o menos elevados. La preferencia por la forma propicia la relación de la naturaleza con la moralidad y con el infinito. Kant alude a ambos rasgos, pero considera independiente la belleza natural, como se observa en el texto de la Crítica del juicio que hemos mencionado anteriormente.

Partiendo de estos mismos conceptos, Schiller entiende que la belleza une al alma con el infinito, la belleza natural - forma de la naturalezamanifiesta, a la vez, infinitud y bondad. En Poesía ingenua y sentimental también argumenta esa relación: «Como este interés por la naturaleza se funda en una idea, sólo puede manifestarse en espíritus que sean sensibles a las ideas, esto es, en espíritus morales» ${ }^{6}$. Aquí, moralidad significa una elevación del alma, por la que ésta es capaz de admirar la belleza natural. En otra ocasión, y tras describir algunos elementos bellos de la 
naturaleza, Schiller llega a la siguiente conclusión: «No son esos objetos mismos, es una idea representada por los objetos lo que amamos en ellos» ${ }^{7}$. El amor es de la idea, la forma, no de la materia.

Kant, Hölderlin, Schelling y Schiller reconocen un vínculo del alma con la naturaleza y, ya sea desde la descripción poética o desde un análisis conceptual, defienden ese vínculo y ponen de relieve su solidez. Lo bello de la naturaleza produce regocijo espiritual. El alma goza con la contemplación de ese espectáculo que le resulta ajeno y a la vez cercano, con el que comparte un origen, en el que halla un reflejo de sí.

\section{LOS OJOS DEL ALMA VEN LA BELLEZA}

En la relación de naturaleza y alma interviene la belleza, que habita en lo formal, lo intelectivo, lo superior. Así se aprecia en las alusiones que los románticos suelen hacer a la belleza. Uno de los presupuestos implícitos en esa consideración, es la de identificar la belleza con el conocimiento y la verdad. Entre otros ejemplos que podríamos traer a colación están los versos de Schiller en su poema Los artistas:

Sólo por la puerta oriental de la belleza

te abriste paso en el país del conocimiento.

Para acostumbrarse al supremo esplendor

se ejercita el entendimiento en la belleza.

[...]

Ceñida con el cinturón de la gracia

se hace niña para que los niños la comprendan:

Lo que recibimos aquí como belleza

se nos presentará un día como verdad.

En la identidad de verdad y belleza, permite considerar a la belleza como verdadero camino y acceso a la sabiduría. Belleza es verdad y posibilidad de hallarla. Es la verdad y su presentación. Contemplando la belleza se aprende a conocer. La belleza hace asequible el conocimiento

7 Friedrich Schiller, Sobre poesía ingenua y poesía sentimental, p. 68. 
más alto, que podría resultar difícil de alcanzar. La dificultad de penetrar lo verdadero la supera la belleza. Esta misión o poder que se le atribuye, no es en absoluto trivial. Además de sostener toda una teoría de lo bello y orientar otras posibles sobre el conocimiento y sobre la misma condición humana. A más de, claro está, aportar una original comprensión del arte y el artista, como se verá más tarde. Pero antes, merece la pena considerar algunas cualidades más a cerca de la belleza y su vínculo con el alma.

Esas propiedades que atribuye Schiller a la belleza, se dejarán notar singularmente, según el mismo autor, en cada sujeto humano que se deje guiar por ella, ejerciendo una transformación en su alma, otorgándole nueva vida. Ella tiene un poder y fuerza especiales: reanima al espíritu y nos diviniza, nos hace libres y puros:

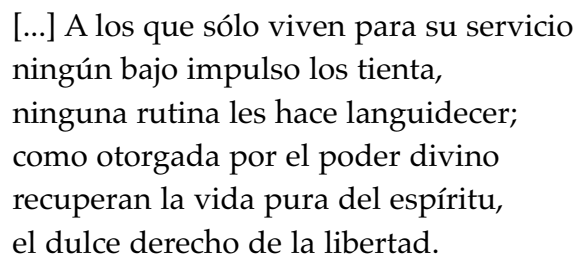

Además de un profundo y patente lirismo, los versos aquí transcritos contienen implícitas definiciones de lo humano, unidas a una peculiar manera de entender la belleza. El encuentro con la belleza resulta crucial en la vida humana, puesto que supone la posibilidad de que ésta alcance su plenitud, su más alto grado, su mayor desarrollo y cumplimiento. Éste viene a ser un eje del pensamiento desde casi los más remotos textos de los que tenemos noticia. De diverso modo, ha habido quienes, a lo largo de la historia, han considerado que la belleza transportaba el alma a un mundo más elevado: la «armonía» para los pitagóricos, o «el mundo de las ideas» platónico, como Plotino o Ficino.

Cierta continuidad con ese platonismo la hallamos en Winckelmann, cuya influencia en ellos se deja notar con claridad. Algunas de las conclusiones a las que él llega por sus estudios y su reflexión son celebradas y acogidas con la mayor atención por el círculo de Jena. Por ejemplo, la 
diferencia entre lo sensible y lo espiritual en la captación de la belleza, la explicación de que ella misma no es algo material ni físico, por lo que no se aprecia a través de un órgano sensible. «La belleza es percibida y gozada por los sentidos, pero reconocida y sentida por el espíritu» ${ }^{8}$.

Lo bello goza de cualidades singulares debidas a su inmaterialidad. Ha de ser incorpórea la fuerza que hace renacer al espíritu y le libera de las bajas pasiones, que infunde vida al alma y prepara un acercamiento a lo divino:

La belleza suprema reside en Dios. La idea de la belleza humana se perfecciona en la medida de su conformidad y su armonía con el Ser Supremo, con este ser que la idea de la unidad y de la indivisibilidad nos hace distinguir de la materia ${ }^{9}$.

Estas perfecciones de la belleza — que sea una e indivisible-, exigen su inmaterialidad porque la materia es divisa y múltiple. Por todo ello, son los ojos del alma los que perciben la belleza.

Describir esa inmaterialidad no es fácil, pero tampoco imposible. Winckelmann lo intenta en una argumentación que recuerda las observaciones de Ficino a la idea platónica descrita en El banquete ${ }^{10}$. El autor alemán emplea el término indeterminación (por contraste con una determinación material), en el sentido de límite y concreción físicos. Escribe Winckelmann:

Llamo indeterminación a la belleza que no se compone de otras líneas ni de otros puntos que los que estrictamente constituyen la belleza; por consiguiente, tal figura que no caracteriza ni a ésta o la otra persona en particular, y que no expresa ninguna pasión o movimiento del alma que interrumpa las formas de la belleza o destruya su unidad ${ }^{11}$.

Johann Joachim Winckelmann, Historia del arte en la Antigüedad, lib. IV, secc. II, p. 183.

Ibid., parág. 42, o.c., p. 185.

${ }_{10}$ Resulta llamativo el paralelismo entre el comentario de Ficino defendiendo que «la proporción del cuerpo no es cuerpo alguno", en su Comentario al banquete, y el texto de Winckelmann aquí citado.

${ }^{11}$ Johann Joachim Winckelmann, Historia del arte en la Antigüedad, o.c., parág. 43, p. 185. 
Otro modo de especificar la inmaterialidad de la belleza es el desinterés. Todo lo material puede suscitar algún interés en nosotros, ya sea de utilidad o de placer. En cambio, la valoración de la belleza ha de ser del todo independiente, incluso no ha de afectarle que el objeto de la apreciación exista realmente o no. Así lo propone Kant:

La satisfacción que determina el juicio del gusto es totalmente desinteresada. Se quiere saber tan sólo si esa mera representación del objeto va acompañada en mí de satisfacción, por muy indiferente que me sea lo que toca a la existencia del objeto de esa representación ${ }^{12}$.

Luego la satisfacción es sobre la representación, no sobre el objeto. Aquí, la posible inexistencia real del objeto contribuye a reafirmar y reforzar el desinterés de la belleza. Este desinterés se apoya en la inmaterialidad, a la vez que la evidencia. Por el desinterés sabemos que no se trata de nada que pueda provocar un estímulo sensible ajeno al puro juicio estético.

Schlegel comparte la tesis kantiana del desinterés, pero le añade como una aclaración acerca de lo importante que es esa dimensión desinteresada para los humanos, y se refiere al objeto bello sin conjeturar sobre su existencia real:

[...] Es el objeto, válido en general, de una complacencia desinteresa$\mathrm{da}$, la cual es igualmente independiente de la fuerza de la necesidad, libre y sin embargo necesaria, completamente inútil y sin embargo absolutamente útil ${ }^{13}$.

El desinterés que subrayan Kant y Schlegel, entre otros, se debe precisamente al carácter espiritual de lo bello en cuanto tal. Es un desinterés por parte del cuerpo: él no recibiría algo ni útil ni placentero. El placer, el gozo o la satisfacción que se experimentan serían únicamente del alma.

${ }^{12}$ Immanuel Kant, Crítica del juicio, o.c., parág. 2, p. 162.

${ }^{13}$ Friedrich von Schlegel, Sobre el estudio de la poesía griega, p. 81. 
Sólo así podemos esperar que lo bello llegue a ser «objeto de una satisfacción universal» ${ }^{14}$.

El desinterés descubre una capacidad genuinamente humana, porque está libre de toda necesidad física e instintiva. Desinterés es un modo de enfatizar que no se da necesidad física alguna. Al mismo tiempo, se trata de una de las experiencias más agradables que los humanos podemos disfrutar y, en ese sentido, resulta máximamente valiosa.

\section{LA MISIÓN DEL ARTISTA}

«El poeta es el custodio de la naturaleza» ${ }^{15}$. Naturaleza es el origen, la pureza, autenticidad y perfección. La idea de naturaleza y belleza que se viene planteando es coherente con una comprensión concreta del papel del artista, el poeta y de su misión redentora que se descubre en la relación del hombre con la belleza, y que queda expuesta en textos como Los artistas de Schiller o Himnos a la noche de Novalis. La libertad a la que aluden estos dos autores y otros, a los que se ha hecho referencia anteriormente, es fruto de la liberación respecto de un estado previo de esclavitud, degradación y bajeza del que la belleza liberó al hombre por la elevación y fortalecimiento de su espíritu. Esta idea de liberación y elevación está presente en varios de los autores de que venimos tratando, si bien no siempre acompañado de un sentido redentor tan cercano al cristianismo.

En la poesía, esta redención se cumple especialmente porque es un arte de la intimidad. «En ella todo es interior: así como los otros artistas llenan nuestros sentidos exteriores con sensaciones agradables, el poeta llena el santuario interior de nuestro espíritu con pensamientos nuevos, maravillosos y placenteros» ${ }^{16}$. Tales personajes han de estar revestidos, forzosamente, de una admiración y grandeza inigualables. La belleza es perfección, lo más elevado; y los poetas y artistas son los que pertenecen a ese mundo y lo hacen asequible a otros. Gracias a los artistas, podemos

${ }_{14}$ Cfr. Immanuel Kant, Crítica del juicio, o.c., parág. 6, p. 174.

${ }_{15}$ Friedrich Schiller, Sobre poesía ingenua y poesía sentimental, o.c., p. 86.

${ }^{16}$ Novalis, Enrique de Ofterdingen, p. 106. 
gozar lo bello que ellos consiguen atrapar y presentárnoslo de modo más fácil. Para esta corriente que analizamos, el poeta viene a ser como un sacerdote que une al hombre con lo divino, que hace de vínculo entre lo humano y lo sagrado. Un buen ejemplo se encuentra en Enrique de Ofterdingen, donde se describe a los artistas de tiempos remotos que habitaban en los bosques:

Estos hombres debieron ser al mismo tiempo oráculos y sacerdotes, legisladores y médicos, porque su arte mágico era capaz de hacer descender a este mundo a los seres más elevados. Con el extraño son de maravillosos instrumentos, despertaban la secreta vida de los bosques y los espíritus que se escondían en las ramas de los árboles; hacían revivir las simientes y convertían regiones yermas y desérticas en frondosos jardines ${ }^{17}$.

Los que comparten la idea de belleza a la que nos referíamos más arriba, coinciden también en este modo de comprender el arte y los artistas. Entre otros, Schlegel, realiza afirmaciones muy parecidas en Sobre el estudio de la poesía griega, a la vez que - como Hölderlin en Hiperión o Schiller en Poesía ingenua y sentimental - contrapone la literatura alemana de sus contemporáneos a la de Grecia clásica, subrayando las cualidades del verdadero poeta:

En la historia moderna del arte encontramos aquí y allá poetas que en medio de una época hundida, parecen ser extranjeros procedentes de un mundo más elevado. Con toda la fuerza de su ánimo buscan lo eterno, y aunque en sus obras todavía no alcancen totalmente la armonía y la satisfacción, sin embargo aspiran tan fuertemente a ellas que despiertan la más justa esperanza de que la meta de la poesía no siga siendo eternamente inalcanzable si es que puede ser alcanzada por medio de fuerza y arte, de cultura y ciencia ${ }^{18}$.

Este concepto de lo artístico trasciende y se aleja de lo que en nuestra cultura - me refiero al inicio del siglo veintiuno en Europa - se suele entender por arte, porque desde el final del romanticismo, se disuelve casi

17 Ibid., p. 107.

${ }_{18}$ Friedrich von Schlegel, Sobre el estudio de la poesía griega, o.c., p. 60. 
por completo el vínculo que éste mantuvo anteriormente con la belleza. Con esa ruptura se generaliza una idea de artista, que guarda muy escasa relación con el artista del que hablan Schlegel y su círculo de amigos. Para ellos, arte no era producción, ni sólo lenguaje, ni mucho menos experimento; posibilidades, todas ellas que - en el siglo veinte- pusieron en crisis la definición misma de arte. Por ello, hemos de reconocer que las tendencias del círculo de Jena no consisten en magnificar todo lo artístico, sino en concebir el arte como algo derivado de una determinada comprensión previa de la belleza.

Para salvar este abismo histórico, no basta elevar al máximo exponente la concepción de arte que nosotros hemos heredado, sino que después de librarse de ella, deberíamos acudir a las tragedias griegas, a los diálogos platónicos, a la Poética de Aristóteles. Sólo después de un esfuerzo comprensivo en esa dirección, estaríamos en condiciones de entender el concepto de arte de los pensadores del romanticismo. En su contexto los artistas se constituyen en guardianes de la dignidad humana:

La dignidad del hombre ha sido puesta en vuestras manos, ¡conservadla!

¡Ella se hunde con vosotros! ¡Con vosotros se alzará!

La magia sagrada de la poesía

sirve a un sabio plan del universo,

silenciosamente conduce al océano

de la gran armonía ${ }^{19}$.

No hay reparo en vincular al artista con algo sagrado. Tampoco en reconocer a los poetas el mérito de la armonía entre el hombre y el universo. El mismo orden que impera en el cosmos es el que el hombre ha de descubrir y compartir, del que ha de participar para elevarse hacia su plenitud. Y en esa plenitud se incluye el encuentro con lo divino. El que consigue llegar a ese estadio es el genio:

${ }_{19}$ Friedrich Schiller, Los artistas. 
Este concepto eterno del hombre en Dios como causa inmediata de sus producciones es lo que se llama genio, lo divino inherente al hombre. Es, en cierto modo, una parte de lo absoluto de Dios. Por eso, todo artista no puede producir más que lo que está ligado en el concepto eterno de su propia esencia de Dios. Cuanto más se contempla el universo en éste tanto más orgánico es; cuanto más enlaza lo finito con lo infinito, tanto más creador ${ }^{20}$.

Como ocurría en la belleza, y de modo parecido a como lo enunciara Platón en El banquete, la armonía se une a lo perfecto, y éste a lo sagrado, y a lo inmutable, y a lo divino. Así es la ascensión del alma a la Belleza.

\section{CONCILIAR ALMA Y CUERPO}

La relación del alma con la naturaleza, lo bello y el arte, se ha ido plasmando al hilo de textos que pueden considerarse pertenecientes al Romanticismo y que no distan más de una década, anterior o posterior, a 1800. La armonía del universo es reflejo del espíritu, manifestación de cierta presencia divina. La belleza es un modo misterioso en que lo espiritual del hombre vibra, crece y goza. El poeta deviene artífice de la unidad de materia y forma, y en la poesía hallamos un modelo para esa unión. Todo ello prepara y supone un modo original de abordar el problema mente-cuerpo. El planteamiento de este problema adquiere en este contexto una nueva luz. Al recorrer esta trayectoria acerca de la experiencia de lo bello y la actividad del alma, se disipan algunas sombras que suelen empañar la interacción de lo espiritual y lo físico.

Ciertamente la relación materia-forma obtuvo una solución por parte de Aristóteles. La exposición de la fórmula hilemorfista en toda su obra, y especialmente en la Física y la Metafísica, ofrece respuestas relevantes. A pesar de ello, la comprensión de lo formal, de aquello que determina la esencia, lo espiritual, ha tropezado repetidamente con objeciones de enfoque empirista. El modo en que se articulan esas dos realidades es siempre difícil de comprender y explicar. La observación de ese binomio

${ }^{20}$ Friedrich Schelling, Filosofía del arte, parág. 63, p. 102. 
con frecuencia desemboca en dualismo o monismo, ambos reduccionistas. Por esta razón, el modo en que los románticos abordaron la presencia del espíritu en el hombre resulta meritorio y útil. En efecto, se trata de textos con una fuerte carga simbólica y poética, a la vez que provistos de fondo metafísico. Los pensadores pertenecientes a este período eran, todos ellos, buenos conocedores de la cultura clásica y, por tanto, de los principios aristotélicos y platónicos más relevantes.

Contamos con ejemplos en que se explicita todo ello. Por ejemplo, el modo en que Schelling entiende el cuerpo en La relación del arte con la naturaleza:

Siguiendo las ideas comunes, consideraréis, indudablemente, la configuración de un cuerpo como una limitación que le ha sido impuesta; pero si os fijáis en la fuerza creadora, os aparecerá manifiestamente como una medida que ésta se impone a sí misma y en la cual se revela como una fuerza verdaderamente inteligente y sabia. Pues en todas partes la facultad de someterse a sí misma a una medida es mirada como una perfección, e incluso como la más alta perfección ${ }^{21}$.

El texto concede una clara preeminencia al espíritu sobre el cuerpo, aunque la propuesta es extremadamente conciliadora: supera el dualismo, el enfrentamiento y la oposición; y se abandonan las connotaciones negativas de que se han llenado, con frecuencia, las aproximaciones al cuerpo. El cuerpo es algo que el alma asume, sobre lo que ella domina sin oprimir; tomándolo incluso como manifestación de sí, sirviéndose de él para exteriorizar su propio orden y excelencia.

A la vez, esa armonía entre cuerpo y alma no se toma ingenuamente como algo dado y siempre logrado. Más bien es una tarea que exige ejercicio, virtud, y que hay que aprender. Se necesita un esfuerzo, pero nunca violencia. Schelling y Schiller, por citar autores concretos, no consideran el estado natural del hombre como absolutamente bueno. Ambos reconocen la necesidad de una educación, de una formación y hasta de una

${ }^{21}$ Id., La relación del arte con la naturaleza, o.c., p. 72-72. 
redención, como vimos más arriba. Pero esa tarea es posible y ellos proponen una vía de actuación: la educación a través de la belleza: ofrecer al alma modelos de orden y equilibrio que le resulten agradables, enseñarle a gozarlos y complacerse en ellos, en su proporción y medida. De este modo, las pasiones e instintos más bajos, cuya presencia en el cuerpo es innegable, puede ser reconducida, apaciguada y adiestrada hasta su más estrecha compenetración con el espíritu:

Aquí nos encontramos con aquel precepto de la teoría que ordena moderar, hasta donde sea posible, las pasiones cuando estallan, a fin de que la belleza de la forma no sea violada. Pero creemos que el precepto debe ser modificado para que exprese esto: las pasiones deben ser templadas por la belleza misma. Pues es muy de temer que esta moderación que se recomienda sea entendida de un modo negativo, siendo así que la verdadera ley del arte es más bien oponer a la pasión una fuerza positiva. Pues lo mismo que la virtud no consiste en la ausencia de pasiones, sino en la fuerza del espíritu que las domestica, así no es descartándolas o aminorándolas como se produce la belleza. La fuerza de las pasiones debe mostrarse ${ }^{22}$.

El texto es de Schelling, pero el contenido coincide plenamente con el idealismo que rige textos tan dispares como las Cartas sobre la educación estética del hombre, los Himnos a la noche o Hiperión.

La contemplación de la belleza proporciona la capacidad de ordenar al hombre en su interior y aplacar las pasiones del cuerpo hasta lograr una concordancia con las fuerzas del alma. Pero es ésta la que protagoniza el ordenamiento, precisamente por su naturaleza indivisible, causa de sus perfecciones y razón de su excelencia: «En su viva y peculiar indivisibilidad, la conciencia habita y anima este delicado símbolo que es el cuerpo humano» ${ }^{23}$. Pero no acaban aquí los méritos reconocidos a lo bello, en este entramado de lo mental y lo somático. Esa materia corpórea es capaz de belleza y puede presentarse bajo hermosas apariencias gracias a la fuerza equilibrada que lo informa. La presencia del alma se manifiesta en el cuerpo y el alma bella, moralmente ordenada, reviste al cuerpo con el reflejo de

${ }^{22}$ Ibid., p. 84.

${ }^{23}$ Novalis, Enrique de Ofterdingen, o.c., p. 266. 
su esplendor. A esta manifestación corporal de lo bello psíquico Schiller lo denomina gracia.

El término gracia es el mismo que empleara Winckelmann para referirse al movimiento que transmiten las esculturas griegas, los gestos que supieron captar sus ejecutores y que les otorgan tan fascinante expresividad. También está unido al cinturón que Venus prestó a Juno para seducir a Júpiter. El poder del cinturón es el de proporcionar encanto a quien lo luce. El encanto no es idéntico a la belleza, sino algo que suele acompañarla y que consiste más explícitamente en la capacidad de gustar. Ahora bien, ese atractivo es algo que pertenece indiscutiblemente al alma:

Donde se presenta la gracia, allí el alma es el principio motor y en ella está contenida la causa de la belleza del movimiento. Y así se resuelve aquella representación mitológica en el siguiente pensamiento: «Gracia es una belleza no dada por la naturaleza sino producida por el sujeto mismo» ${ }^{24}$.

La imagen mitológica del cinturón es tomada por Schiller como representación de la libertad, porque es un elemento contingente, no necesario; algo de que cada sujeto puede apropiarse si consigue en su cuerpo la manifestación de un alma bella.

\section{CONCLUSIÓN}

Como resumen de lo enunciado, puede destacarse cómo esos pensadores y escritores idealistas tuvieron el acierto de compartir una visión del hombre positiva y esperanzadora: reconocieron la función rectora del alma, sin despreciar el cuerpo, advirtieron las inclinaciones degradantes en los instintos, sin desesperar de la posibilidad de enderezarlos pacíficamente; sus espíritus nobles supieron percibir un orden que penetraba todo. Las consideraciones en que ellos se emplearon vienen a recuperar un equilibrio en el hombre que Schelling expresa certeramente:

${ }^{24}$ Friedrich Schiller, Tratado de la gracia y la dignidad, o.c., p. 13. 
La materia bruta, ciega en cierto modo, tiende a una configuración regular y tiende, sin saberlo, a unas formas puramente estereométricas, que pertenecen, sin embargo, legítimamente, al reino de los conceptos y que son algo espiritual en lo material. [...] Esta fuerza activa es, en la naturaleza y en el arte, el vínculo entre el concepto y la forma, entre el cuerpo y el alma ${ }^{25}$.

Ese vínculo puede fortalecerse, y el equilibrio llevarse a plenitud. Es necesario partir del conocimiento de la naturaleza humana y comprenderla de modo positivo, optimista: ser un poco idealistas y confiar en la posibilidad de equilibrio entre cuerpo y alma, entre sentimiento y razón. A partir de ahí, se abren vastas posibilidades educativas: aprender a armonizar alma y cuerpo a través de la belleza.

${ }_{25}$ Friedrich Schelling, La relación del arte con la naturaleza, o.c., p. 66-67. 


\section{BIBLIOGRAFÍA}

BÉGUIN, A., El alma romántica y el sueño, Fondo de Cultura Económica, México, 1954.

BRION, M., La Alemania romántica II, Novalis, Hoffman, Jean-Paul, Barral, Barcelona, 1973.

FONTÁN, Manuel, El significado de lo estético, EUNSA, Pamplona, 1994.

HERNÁNDEZ-PACHECO, J., La conciencia romántica, Tecnos, Madrid, 1995.

MENÉNDEZ-PELAYO, Estética del idealismo alemán, Rialp, Madrid, 1954.

KANT, Crítica del juicio, trad. M. García Morente, Librería V. Suárez, Madrid, 1958.

NOVALIS, Enrique de Ofterdingen, trad. E. Barjau, Cátedra, Madrid, 1992.

SCHILLER, F., Kallias. Cartas sobre la educación estética del hombre, trad. J. Feijóo, Anthropos, Barcelona, 1990.

1998.

, Poesía filosófica, trad. D. Innerarity, Hiperión, Madrid,

, Sobre poesía ingenua y poesía sentimental, trad. J.

Probst y R. Lida, Icaria, Barcelona, 1985.

, Los artistas, trad. J. Probst y R. Lida, Icaria, Barcelona, 1985.

, Tratado de la gracia y la dignidad, trad. J. Probst y R.

Lida, Icaria, Barcelona, 1985.

SCHELLING, La relación del arte con la naturaleza, trad. A. Castaño, Aguilar, Buenos Aires, 1954.

, Sistema del idealismo trascendental, trad. J. Rivera de Rosales y V. López Domínguez, Anthropos, Barcelona, 1988.

Buenos Aires, 1949. 
SCHLEGEL, Sobre el estudio de la poesía griega, trad. B. Raposo, Akal, Madrid, 1996.

WINCKELMANN, Historia del arte en la Antigüedad, trad. M. Tamayo, Aguilar, Madrid, 1989.

, Lo bello en el arte, Nueva visión, Buenos Aires, 1964. 